\title{
Research Paper: \\ The Process of Discontinuing in the Participants of Narcotics Anonymous Association
}

\author{
Maryam Eskafi $^{1 *}$ iD, Reza Abbaspour ${ }^{2}$ iD \\ 1. Department of Social Science, School of Humanities, Gonabad Branch, Islamic Azad University, Gonabad, Iran. \\ 2. Department of Islamic Jurisprudence, Mashhad Branch, Islamic Azad University, Mashhad, Iran.
}

$\begin{gathered}\text { Use your device to scan } \\ \text { and read the article online }\end{gathered}$
Citation Eskafi M, Abbaspour R. The Process of Discontinuing in the Participants of Narcotics Anonymous Association.
Journal of Research \& Health. 2020; 10(1):43-52. http://dx.doi.org/10.32598/JRH.10.1.43

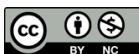

Article info:

Received: 03 Apr 2019

Accepted: 11 Oct 2019

Publish: 01 Jan 2020

Keywords:

Narcotics Anonymous (NA), Mechanisms of substance treatment, Neutralizing techniques

\begin{abstract}
A B S T RACT
Background: This research aimed at studying the process of substance dependence treatment in Narcotics Anonymous (NA) association.

Methods: This qualitative study applied a narrative research technique. The study population consisted of all individuals referring to the Torbat Heydarieh NA association in 2016. The study samples were selected by purposive sampling method. Three group interviews were conducted with 10 NA participants who have treated their substance dependence and always joined the association sessions. Each interview lasted about 4 to 6 hours.

Results: The most critical effects of attending NA sessions may be cognitive and faith-value changes, as follow: raising the awareness of self-illness, its symptoms and how to cope with it, promoting self-awareness and characteristics, and identifying the root causes leading to the condition in each person.

Conclusion: The treatment is oriented towards making the inner police and consciousness in substance dependents. According to David Matza's theory, a deviant person first neutralizes this internal assessing as well as supervising force; then, he/she commits deviance. Completing 12 personal steps is an inward process that shapes the mechanism of recovery in substance dependents.
\end{abstract}

\section{Introduction}

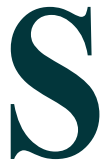

ubstance dependence is a social problem with an apparent prevalence and intensity worldwide. Exploratory interviews conducted by the researcher have suggested that various solutions to this problem had no lasting effects. Studies have investigated drug injection [1] (the suffering of the substance dependents on deciding to treatment) [2], and the methods of substance dependence treatment [3]. Moreover, different meta-analyses [4-10] and some effectiveness research into some solutions [11-15] have been performed in this regard. Their obtained data re-

* Corresponding Author:

Maryam Eskafi, PhD.

Address: Department of Social Science, School of Humanities, Gonabad Branch, Islamic Azad University, Gonabad, Iran

Phone: +98 (915) 3221003.

E-mail: meskafi@yahoo.com 
vealed that associations working on substance dependence have considerably succeeded in managing this problem.

If substance dependence is regarded as a crime, many theories analyzing criminal behavior could be employed [16]. However, the researcher believes that these theories may be able to explain only some of the determining factors in substance dependence treatment; they cannot be employed in this process in the NA association.

As shown in Figure 1, Matza's theory of neutralizing techniques in committing the crime has categorized them into 5 categories 1 .The technique of denying responsibility. 2. The technique of denying damage or cost. 3 . The technique of denying the victim. 4 . The technique of loyalty to favorite groups. 5. The technique of condemning the police force. According to Matza, the criminal youth using this technique divert the attention of the society from their actions and make them notice the ones who condemn him. In his view, the condemner who is hypocritical and out of personal grudge acts this way [17] The substance dependents view the abundance of drugs in the society as a reason for justifying their consumption and the responsible controlling force not fulfilling their duties. Examining different empirical and theoretical effects indicated that the process of substance dependence treatment had been overlooked in interviews with the NA participants; however, most of them have studied it from other aspects, such as familial, personal, and environmental factors.

Based on this, the researcher aimed to find the answer to the question of how the process of substance dependence treatment is among the participants in order to be treated.

\section{Methods}

The present qualitative research applied a narrative method. To explore the process of substance dependence treatment in the NA association, it was necessary for the researcher to discover the narratives by the substance dependents from the beginning to the cure; it was considered as a story to find out the consecutive periods they experienced in their lives. Ten people were selected employing a purposive sampling method. The first criterion for this selection was to choose the ones who were willing to answer the questions in detail in numerous sessions.

The second criterion was the principle of the maximum variety, in terms of age, occupation, and marital status to reach the saturation point. The required data were obtained in three in-depth group interviews. Each interview lasted about 4 to 6 hours. The interviews were recorded after obtaining permission from the interviewees. Then, they were transcribed and the repeated sentences were eliminated. The verbal statements were transcribed the way they had been expressed to prevent data distortion. After transcription and saving the data, coding and creating the system of categories for the research topic, and finally, the analyses were performed. The data text analysis was executed according to Strauss and Corbin [18] After the transcription and saving of the data, coding and creating a categorical system were conducted.

Moreover, by narrative research techniques, the collected data were analyzed. In over 6 months, coding was repeated several times by two research assistants. Furthermore, the categories and concepts were scrutinized to uniform the codes. Next, the concepts were classified to observe research reliability. Two research assistants designated the codes, decided about their similarities and

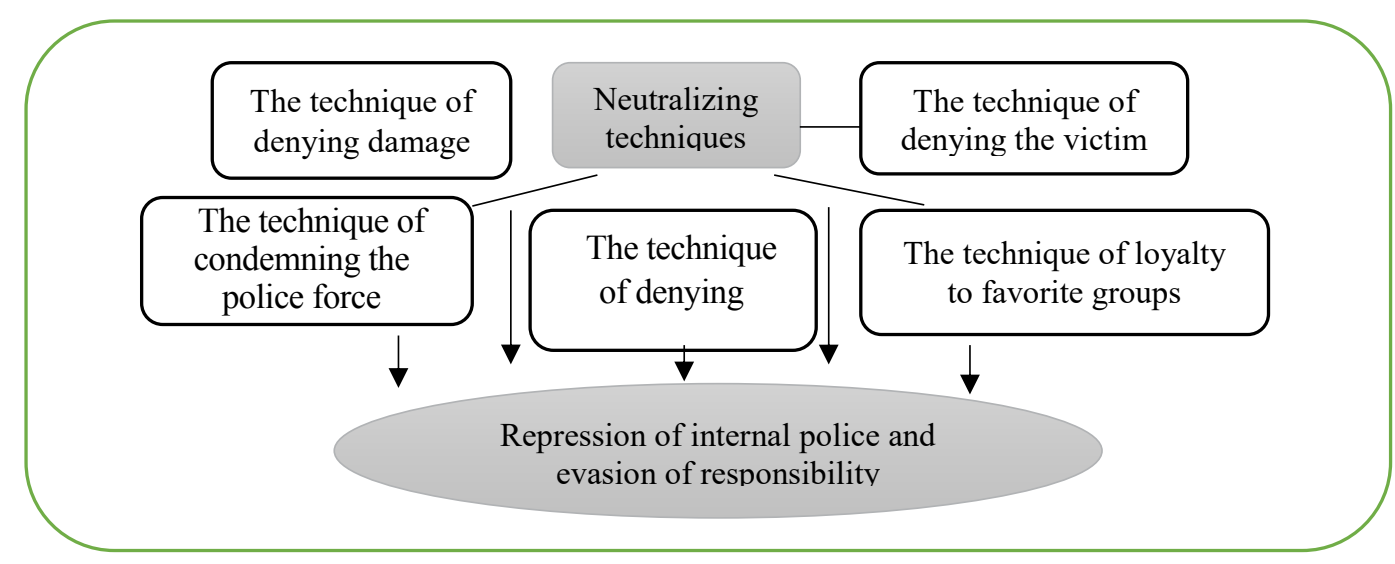

Figure 1. Meta-neutralization techniques to rationally justify diversion by the offender 
differences and reached an agreement to select the best code to refer to the respondents frequently. This process helped to confirm the extract concepts and categories, raising the study validity.

\section{Results}

The coding results have been summarized in 4 main themes. Each theme or stage includes the categories briefly listed in Table 1.

The conflict between desire and rationality included the following concepts

The process of capturing rationality: First, the substance dependents experience this stage. One of the path-seekers stated that: "The more I did drugs, the higher dose of various drugs I consumed; it means; first, I would get high by a little opium worth 5 Tomans, then I would have increased the dose to worth 10 Tomans and it would have gradually gone up ...I only thought about feeling better...after a while, I went to the NA, I did not know what was going on, because I was living in such an unreal world at that time that I could not even understand what the people said at the reception about the activities.... Then, there was a cycle to stop the consumption which they said was better than going there again. Because your mind is free, feeling drugged can disappear, as the substance dependents live in an unreal world" (33-year-old, AA degree, businessman, has a child). Thus, the action that begins with simple, scattered substance use, results in absolute hedonism in the person over time by increased pleasure.

\section{The collapse of rational, positive thinking}

The process of hedonism gradually comes along with the collapse of rational, positive thinking. The person's goal and meaning in life will become the repeated pleasure derived from drugs and his/her life is oriented towards this. If I did not do drugs, I would not be able to survive To obtain drugs, I would do anything, and nothing would stop me, I was so drugged that I behaved like animals" (45-year-old, bachelor's degree, clerk, has 2 children).

"When drugged... no word carried weight, I did not care about myself, and I did not follow their talks to tell them to start the job. When drugged, I did not think about these things, I just thought about working to consume and consuming to work; this cycle repeated constantly". "I reached a point that I had to consume; just like alive people need water, food and air to survive, I needed drugs to do so.

\section{Negative programming rationality}

In this stage, rationality loses its critical and preventive characteristics and becomes pleasure-oriented and supports the person's hedonistic activities. For instance, someone said: "at first when I denied it, I said I would start from the next semester, I took a semester off, it was all a lie, I took a long time off, they asked me why I did not leave and I answered I would go, I do not like this major" (27-year-old, diploma, businessman, single).

\section{The collapse of the supportive structures}

In this stage, the person lies and becomes doublefaced and deceives others. They betray other's trust, and consequently, people do not put their social trust in them anymore. Thus, they gradually lose their social capital and a robust social network. Moreover, the person moves toward personality instability, which consequences job insecurity.

"I changed many jobs just because of doing drugs because if I did not have drugs, I would not be able to work; in the middle of the work when I got drugged I would have left the workplace, I would have escaped

Table 1. The process of substance dependence treatment regarding the main themes and categories

\begin{tabular}{|c|c|c|c|c|}
\hline Main Themes & Recovery Mechanisms & $\begin{array}{l}\text { Willingness to Change the } \\
\text { Lifestyle }\end{array}$ & $\begin{array}{l}\text { Recovery Throug } \\
\text { h Interaction }\end{array}$ & $\begin{array}{c}\text { The Impacts and } \\
\text { Consequences of the } \\
\text { Association }\end{array}$ \\
\hline \multirow{4}{*}{ Sub-categories } & $\begin{array}{l}\text { The conflict between } \\
\text { desire and rationality }\end{array}$ & The association as a tool & $\begin{array}{l}\text { Collective resistance to con- } \\
\text { sumption }\end{array}$ & Boosting self-esteem \\
\hline & $\begin{array}{l}\text { Negative program- } \\
\text { ming rationality }\end{array}$ & $\begin{array}{c}\text { Steady care and rational } \\
\text { supervision }\end{array}$ & $\begin{array}{l}\text { Collective support against } \\
\text { consumption }\end{array}$ & Altering beliefs \\
\hline & $\begin{array}{l}\text { The collapse of the } \\
\text { supportive structures }\end{array}$ & \multirow{2}{*}{\multicolumn{2}{|c|}{12 steps and meaning }} & $\begin{array}{l}\text { The transformation of } \\
\text { life meaning }\end{array}$ \\
\hline & $\begin{array}{l}\text { reaching the end of } \\
\text { the line }\end{array}$ & & & \\
\hline
\end{tabular}


doing drugs, so my boss told me not to come back the day after" (37-year-old, married, no child, welder, elementary school).

Personality instability and subsequent job insecurity cause the person to lose his/her socio-economic status and support. In this stage, agony overcomes pleasure and hesitates the person about choosing between the pleasure of drugs and accepting the affliction of social exclusion. This hesitation and increased cost of drug access gradually make the person reach the stage called "reaching the end of the line".

Reaching the end of the line: The collapse of the supportive structures, especially the support from the ones close to the person, gradually causes him/her to reach the peak resistance. In this stage, the pain outweighs the pleasure; the person asks himself if it is worth consuming drugs. A person stated that: "When I saw that my wife had left me and no one respected me, my brother would do drugs and did not hold me in awe, I reached a point that I could not tolerate it anymore. I think most of my friends died due to overdose, I saw many things and I liked them, but I reached a point that I had to accept the NA as a solution to my big problem, called addiction. When my reasons do not justify me anymore, that is the end of the line. I always had some reasons for myself; when someone asked me why I did drugs, I would have said I have a backache or a kind of disease, so if I did not do drugs I would not be able to live.. " and also: "I always said drugs were fine and very interesting and I enjoyed it a lot, if you do drugs now you will enjoy, but now that I have joined the NA, it is like 100 million Tomans; it is not worth it if I have to live in misery or go to the prison or commit theft or talk back to my parents or swear at my wife... when I reached this point, I decided to quit it".

Another person said:" my family, my parents, and my sister did not tell me no to come, but I saw something in their look telling me not to come to the proposal ceremony, I was hopelessly substance dependent. I could not manage anything and tell my family to go somewhere or not; they decided by themselves, my child became the top student and his picture was on a banner and it was in the city for 4 days but I had not seen it as his father and I did not know that he was the top student. Once, I took him to school and I saw the picture and I asked him about it and he said that he had become the top student in the province and this encouraged me to come to the NA". However, how and when people reach the end of the line differ from one person to another. "There is somebody in the NA association who did drugs for 18 months, from the time he started until he reached the peak of that...a rich man was doing drugs, the bank called him and told him that his check had bounced and they wanted to cash the check by withdrawing from his saving account; then, he got up and found out that he was so dependent on drugs that he had got into trouble, then he went to the NA and got treated... There was a person from Torbat that his friends helped him with his substance dependence treatment, he lived in the cemetery, he would sleep in the grave dug for the dead at night, several times they took him to the NA but it was useless..."(47-year-old, teacher, has 3 children, bachelor's degree).

\section{Willingness to change the lifestyle}

In the next stage, rational thinking emerges again in individuals. The desire to return to a healthy lifestyle without the pleasures derived from drugs is created in them. An individual stated that:" I did not have control over my life. I wanted to live healthily, like many other people. I wanted to be a good child, spouse, and neighbor" (28-year-old, married, no child, under diploma, military man).

The NA association as a tool: One of the subjects regarded the NA association as a medication (as a cure) for biopsychological health". I am using NA principles as medicine and if I abstain from that, my illness relapses and there was no guarantee that I would have quitted drugs 5 years ago"( 29-year-old, single, elementary school, waiter).

Regular care and rational supervision: In this stage, when the person has just become familiar with NA, he/ she should be persistent and should resist the temptation to consume drugs.

"Because I am physically different from normal people... I take codeine, but my mind does not know whether it is for pleasure or cure, so I avoid it. Because of physical problems, my body becomes dependent easily; e.g. when somebody suffers from people with diabetes he/she never goes to the sweets shop....and because I am substance dependent and my body is like this, I try to avoid some things, I have some do's and don'ts. Since I have this problem, I have to follow a specific way of life" (30-year-old, single, unemployed).

An individual believed that this constant supervision should continue throughout the whole life". I have a desire to smoke till I am dying, I mean if somebody near me starts smoking, I feel like smoking too, but there is something that prevents me; I know that if I start, I 
will not be able to control it and I will be back to the first stage. I want to smoke, but smoking cheapened and weakened me, etc". (35-year-old, driver, under diploma, has 2 children).

\section{Recovery through interaction}

The facilitating and differentiating matter in the process of recovery in NA is its materialized process through interaction and communication via a goal-oriented collective action. in other words, the social support of the travelers (the substance dependents joining NA) help each other progress. Communicative rationality plays an essential role in this regard. The interaction is obtained based on not distorting the truth about self, telling the truth to others, talking about it to reach strategies, and objective consequences. In NA, the recovery process is shaped through effective interactions based on consensual truth. One of the travelers explains that he did not know how to express his request before coming to NA". I would always take something from others by force, I could never talk to get something from them. I did not use logics" (37-year-old, married, no child, seeking a job).

Collective resistance to consumption: In this process, confession, negotiation, and collective resistance to consumption occurs, and networking social support is materialized. One of the travelers stated that: "NA is based on the help of one substance dependent person to another via sharing experiences. I have no interest in personality matters, but I am more experienced than Javad about NA; so, he benefits from my experience and I benefit from my mentor... I can say that one of the advantages of these sessions is what is shared and discussed. When a new member joins and I talk to him, he says one of the best things about the sessions is that you do not feel tempted to do drugs anymore..... it means when I get in touch with others when I stop doing drugs, and I declare it in the sessions after 24 hours, I cannot wait for the session to start at 7 o'clock. Well done! you helped me and for the last 24 hours, I haven't done it" ( 38-year-old, married, 3 children, businessman).

Mutual support against consumption: During the sessions, mutual support against consumption is created. Thus, each NA member feels that their effort to refrain from drugs even for 24 hours is acknowledged and appreciated by the sympathetic others. This steady social support provided to each other reinforces the sense of belonging to each other and social support. Its consequences are increased personal willpower and incentives. The following statements by an interviewee reveal such support: "your sessions are a kind of moral exam- ple, I think that when a person who has been hopelessly dependent on substance goes to the session one night and his willpower becomes so strong that he cannot wait to declare he has not done drugs for 24 hours and then continues that to 5, 6, and 10 years. It is great; this session boosts your self-confidence, willpower, and patience".

The impacts and consequences of the NA association for travelers

In addition to treating substance dependence, attending the NA sessions has had particular psychosocial consequences, mentioned below.

\section{Boosting self-esteem and awareness}

A significant and obvious consequence of frequent attendance to the sessions is self-evaluating their disease, as well as their personal and psychological suffering. Increased self-awareness of disease facilitates the recovery and creates an added incentive for substance dependence treatment. A traveler stated that: "I became aware of it in NA, this disease is called addiction... I am aware that of its most apparent symptoms is doing drugs... because I am substance dependent, I see what the NA association means, I am not just a passive listener".

\section{Boosting self-esteem}

Inner voids and consuming drugs: A major problem among substance dependents is their effort to compensate for their psychosocial defects through drugs. One of the travelers explained how he used drugs to make up for his poor social interactions.

"The first time I did drugs it was out of curiosity. I wanted to know what effects it would have on me... Moreover, it was fascinating, because when I did drugs for the first time, I felt that it was the answer to all my questions. I mean it boosted my self-confidence. I, the one who could not speak in a gathering and was reclusive, turned to a gregarious person using this stuff".

For some other substance dependents, consuming drugs fills some of their mental voids. Drugs can make up for their emotional and mental defects. "Drugs filled that void in my life; then, I felt it was my shelter". Although consuming drugs at first gives a false feeling of power and fills their voids, the constant use of that has profound harmful effects in the long run. This occurs after the false feeling disappears and just the drug dependency remains. 
The reduction of human value: As mentioned before, due to consuming drugs and becoming dependent on it, supportive structures and secure networks gradually collapse. A significant consequence of that is the person's reduced value in the eyes of others. The travelers have often mentioned the afflictions of being excluded.

"I was in a stage in which if I had money, cigarette, a place, or something I would be respected for...". Even when a substance-dependent person did not feel like doing drugs, he was told to shut up. This is because he had done it before and he would do drugs again; nobody respected our desire".

The affliction of being excluded attracts the people to the NA association. Furthermore, the most important thing happening to them is entering a place where receiving, welcoming, and collective cherishing is felt by a newcomer; he/she is readily accepted and supported by the others.

"I came somewhere they respected my desire, for me who had no clothes to wear and did not know how to speak, the NA association valued me, and it was a good event".

"It was the first time I had entered a place where they liked me because of me; they did not ask for anything, no condition at all. They did not ask for money, or even they did not ask my name, they did not care if was rich or poor".

The restoration of supportive systems and boosting self-esteem: An exciting event in the recovery process of travelers is that after attending the NA and obtaining social support and starting recovery, gradually, due to their behavior modification, their previously disturbed social life improves; furthermore, people close to them who observe their transformation, trust and support them. This boosts their self-esteem. One of the travelers mentioned that: "when he wanted to get married, they gave many responsibilities to him, which helped the restoration of their faith in me... "I had a bakery before attending the NA, I have it now, they did not trust me, I had to steal things because of my addiction, some people had to watch me out to prevent me from that, but they could not; it is 8 years now that I have been in the bakery. They trust me and ask no questions".

\section{Beliefs alteration}

Another necessary consequence of attending the NA association is the alteration of their beliefs about substance dependence and its dimensions. Travelers have often pointed out how attending the association has cre- ated a different attitude towards their illness and people close to them.

The alteration of belief about the cause of illness: Before attending the NA, the travelers usually mention various external factors and some close friends as the causes of their substance dependence. Attending the NA association draws their attention to the fact that the problem is with them.

"One of the greatest symptoms of my illness was that other people who were in a worse situation had caused it".

"In the past, I thought that external factors caused my illness, if I did not live here, I might not be substance dependent, or if I had not made friends with ..., I would not have become substance dependent, but now in the association, I know that the illness is inside me".

Belief alteration about how to treat substance dependence: Attending the NA association makes it clear for the substance dependents on what quitting addiction means. They have a false preconception about substance dependence treatment; i.e. if they stop consuming drugs, they have treated their substance dependence; however, its psychological roots remain in them and due to ignoring the psychosocial causes, relapse is probable. One of the travelers declared that: "That time I was not aware and thought that doing drugs was temporary. I thought as soon as I stopped doing drugs, I would have recovered, and if I started again, I would lose".

Increasing knowledge leads to an elevation of awareness of the illness and its mechanism". My addiction involved 3 aspects; my body, soul, and mind. They were hurt, by taking drugs. My body might get clean, and my mind would be calm by counselling, but my soul poverty would just be alleviated by 12 steps of the principles; it means by practicing and having faith in some principles, you would abstain from harmful things".

\section{The transformation of life meaning}

The main change made in the personal and social lives of the travelers by the NA is creating meaning in their lives again. The life of the substance dependents is limited to the pleasure derived from drugs in the simultaneous gradual process of the collapse of the supportive and social structures and drug dependency, and consuming drugs becomes their only source of meaning in life. Besides, consuming drugs turns to a meaningful pleasure for which the substance dependents sacrifice their other blessings. One of the travelers stated that: "Some of my friends came 

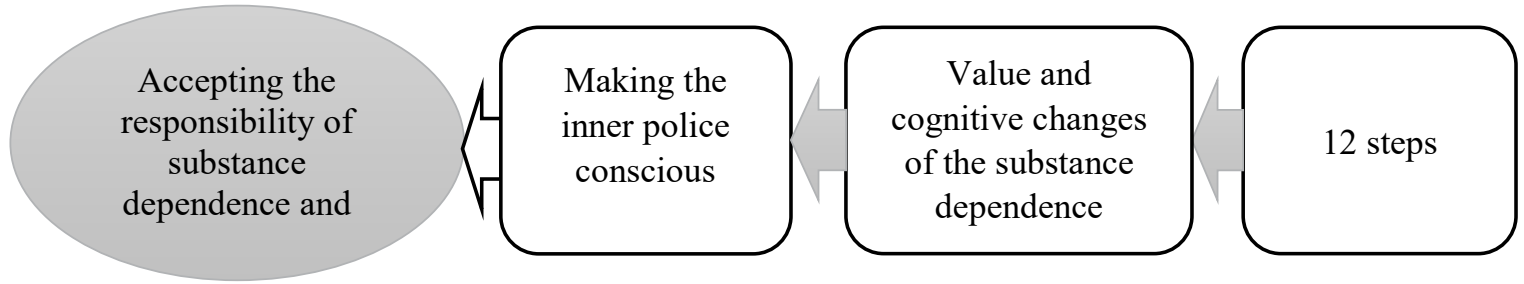

Figure 2. The process of treating the substance dependents in NA (inverted Matza's neutralizing techniques)

with me and for the first time something happened within me. I found my other half, and my life had meaning with drugs. Drugs became everything for me".

"I was told about the NA by one of my relatives. I think the spiritual void I was talking about would be filled by studying, praying, social connections, playing sports, loving their spouse or parents, but I filled it by drugs. When I did drugs, I enjoyed it a lot and said I wish I had tried it 10 years earlier. Then, I felt powerful and worked, studied, exercised, and walked better; something was missing, just like when you want to cook food and think the salt is not enough, the salt of my life was drug, when I did drugs I thought that I was a normal person. I could have loved my wife and my mother and listened to my mom, I did not obey her before. When I was high, I thought I could work for long hours; if I did not do drugs, I would not go to work.

The substance dependents become familiar with the NA; then, become familiarized with the 12 steps. Next, they gradually become aware of their mistakes in the way they have had to fill their inner voids". Therefore, I should confess that my problem was spiritual poverty".

\section{Twelve steps and meaning}

The NA association is a self-helping group. A selfhelping group is a volunteer group whose members coordinate their efforts to overcome a common problem. In NA, the substance dependents are trained to observe the truth and have a chance to live without drugs. The NA performance is based on 12 steps (step is a direction towards health and recovery) which means if a person willing to treat substance dependence tries, in each step, he/she moves towards progress and recovery. These steps have been explained in detail in the booklet of the NA association.

Pursuing meaning while taking the 12 steps and the social atmosphere in NA exposes them in a spiritual direction and transforms their attitude towards life.
"I have entered the NA. Something interesting that has happened to me is that in the past, by doing drugs, I filled the voids but the NA provided me with some simple tools to replace drugs; i.e. the spiritual feeling I sought in drugs, now I try to find by following the 12 steps, including studying, attending a session, contacting my mentor... I joined the NA to boost my spirit in 12 steps, so I have not done drugs for a few years".

Self -knowledge, and meaning: Completing the 12 steps have generated special meaning for the travelers in the NA". I read a narrative by Imam Ali saying the highest level of rationality is self-knowledge... the 12 steps helped me to go from self-knowledge to knowing God, substance dependents person needs faith in God"'. Consider a scale, with personal problems and defects on one side. I am trying to make the other side heavy. Spiritual principles like love or the things which draw me closer to God". Finally, the various steps in the process of substance dependence treatment can be illustrated in Figure 2.

\section{Discussion}

As the study results indicated, the beginning of a recovery in the NA depends on their willpower and attendance time, declaring their desire to recover. Then, the NA warmly welcomes the substance dependents and boosts their selfesteem. Additionally, substance dependence treatment, by making cognitive changes and altering beliefs and providing social support, they are gradually oriented towards recovery. As a result, the NA 12 steps profoundly impact the moral and spiritual transformation of travelers.

Moreover, their personality is deeply influenced. Treating substance dependence in NA is precisely the opposite of Matza's neutralization; in 12 steps, the inner police of the person is awakened. The substance dependents also first accept the responsibility of their deviation and avoid blaming and maligning others. Many research findings [11-15] supported the results of this study. They have generally suggested that NA has had a long-lasting effect in substance dependence treatment and the personal growth of the visitors, in comparison with other associations. 
According to Hirschi's self-control theory, when people create a strong bond with society, they stand a little chance of becoming a criminal. Besides, he believes that dependence, commitment, occupation, and faith connect people to society. In this process, we first observed when a person becomes substance dependent, he/she is gradually excluded from the society which compounds his/ her problem. Thus, if he/she does not reach the end of the line to decide to mend his/her ways, he/she cannot free himself/herself from that. Some research findings [2] have also reported that support plays a vital role in reducing consumption and quitting substance abuse.

Furthermore, some of the present study results are consistent with the general theory of crime. According to this theory, the crime increase in society stems from low selfcontrol in individuals. As a result, the inner police or conscience has not been institutionalized well in the process of socialization and education. This theory is known as low self-control self-police in the criminals. The main cause of the crime is not the poor connection of the person with the society, but the power of controlling behavior. They believed that socialization and education are essential for creating self-control and limiting personal interests [19]. If education and socialization are insufficient during childhood, self-control decreases, leading to hedonist behavior, one of which is committing a crime. In other words, when individuals have to choose between rationality and desire, their self-control has declined and are unable to control themselves; when they are freed, they abstain from crime and revert to the normal state.

According to Matza's neutralization techniques, the cause of the deviation is an internal factor that can neutralize conscience or the inner police of the person and make it stop working. When individuals can overlook their inner police when judging or supervising, they feel practically free and do not feel committed to social values and norms [17]. The present study results revealed that all the sample population was subject to such conditions. However, generally, substance dependence treatment is an inverted process, compared with previouslystated Matza's neutralization techniques.

The most critical consequences of attending the NA association emerge as belief, value, and cognitive alterations. The main cognitive changes are as follows: raising awareness about their illness, its symptoms, and how to face it, raising self-awareness about their personality traits, and identifying the root causes which triggered the illness in them. When the substance dependents first attend the NA association, they notice that their strong desire for doing drugs is an illness that needs to be treat- ed and it is possible to do so. They become aware of how their daily behaviors have been affected by their substance dependence and through which process they have been hurt. The central belief and value changes are as follows: finding the roots of the illness in their mind and soul and avoiding blaming others and understanding the spiritual and biopsychological aspects affecting substance dependence. By attending the association, their beliefs about their illness change. They understand that blaming others for their substance dependence is wrong and they should find the causes within themselves. Regarding the results, it is highly recommended that the substance dependents become educated to expand their attitudes on the truth to know their real personality.

\section{Conclusion}

The NA activities are based on 12 traditions and steps. The traditions include the NA group requirements; the steps are aimed at personal growth, recovery, and mental health. In this respect, the travelers follow modesty and surrender, leave their willpower to the almighty power, know about their most profound moral and personality flaws, and try to compensate the ones hurt by them. They are transformed from a world based on material pleasures to a world based on spiritual ones.

Moreover, with the aid of their mentor, they become familiar with their spiritual side. The substance dependents obtain self-awareness by attending the sessions; the open side grows and expands and this is the beginning of the battle against addiction. This self-awareness is impossible unless they are present in the sessions and express their feelings and obtain collective awareness.

\section{Ethical Considerations}

\section{Compliance with ethical guidelines}

Ethical approval for this article License No $2 / 34951$ historian 6 January 2020 has been registered.

\section{Funding}

This was a self-funded research study.

\section{Authors' contributions}

Study design and data collection and analysis: Maryam Eskafi Noghani; Manuscript preparation: Maryam Eskafi, Reza Abbaspour. 


\section{Conflict of interest}

The authors declared no competing interests.

\section{References}

[1] Fathi S, Razavi MH. Describing how welcoming the citizens of amusement-Sporting parks. Int J Sport Stud. 2015; 5(1):87-96.

[2] Jelleyman C, McPhee J, Brussoni M, Bundy A, Duncan S A cross-sectional description of parental perceptions and practices related to risky play and independent mobility in children: The New Zealand State of Play Survey. Int J Environ Res Pub Health. 2019; 16(2):1-19. [DOI:10.3390/ijerph16020262] [PMID] [PMCID]

[3] Beheshti M H, Hajizadeh R, Faghihnia Torshizi Y, Alami A Samaei S E. Compliance of children's play equipment in urban parks of Gonabad with national safety standards (case study). Iran occupational health. 2019; 16 (3):22-31.

[4] Takano T. Health and Environment in the Context of Urbanization. Environ Health Prev Med. 2007; 12(2):5-51. [DOI:10.1007/BF02898149] [PMID] [PMCID]

[5] Vollman D, Witsaman R, Comstock RD, Smith GA. Epidemiology of playground equipment-related injuries to children in the United States, 1996-2005. Clin Pediatr. 2009; 48(1):6671. [DOI:10.1177/0009922808321898] [PMID]

[6] Beheshti MH, Hajizadeh R, Rahat R, Ali Zadeh F, Davoodi A Investigation of the most important direct cause of occupational accidents based on the Pareto Chart. Iran occupational health. 2015; 12(3):38-45.

[7] Sigaroudi AK, Talebzadeh S, Alijani B, Motevasseli S, Dashtyari S, Davoudmanesh Z, Shariati M. The prevalence of brain and neck injuries in patients with maxillofacial fractures in teaching hospitals of Rasht in 2016. Int J Clin Med. 2017; 8(11):631-7. [DOI:10.4236/ijcm.2017.811059]

[8] Ojaghi SH, Nourizad S, Mahboobi M, Khazaei M, Najafi G. Disaster crisis handling preparedness level of hospitals in Kermanshah. J Kermanshah Univ Med Sci, 2009; 13(3):267-74.

[9] Beheshti MH, Hajizadeh RO, Mehri A, Borhani Jebeli M Modeling the result of hexane leakage from storage tanks and planning a emergency response programm in a petrochemical complex. Iran Occupational Health. 2016; 13(1):69-79.

[10] Saunders NR, Lee H, Macpherson A, Guan J, Guttmann A. Risk of firearm injuries among children and youth of immigrant families. CMAJ. 2017; 189(12): 452-8. [DOI:10.1503/ cmaj.160850] [PMID] [PMCID]

[11] Azadi T, Khorasani-Zavareh D, Sadoughi F. Barriers and facilitators of implementing child injury surveillance system. Chinese J Traumatol. 2019; 22(4):228-32. [DOI:10.1016/j. cjtee.2018.09.003] [PMID] [PMCID]

[12] Spedding RL, Harley D, Dunn FJ, McKinney LA. Who gives pain relief to children? Emerg Med J. 1999; 16(4): 261-4. [DOI:10.1136/emj.16.4.261] [PMID] [PMCID]
[13] Fiissel D, Pattison G and Howard A. Severity of playground fractures: Play equipment versus standing height falls. Injury Prevention. 2005; 11(6):337-9. [DOI:10.1136/ ip.2005.009167] [PMID] [PMCID]

[14] Hart R. Containing children: Some lessons on planning for play from New York City. Environment Urbanization. 2002 14(2):135-48. [DOI:10.1177/095624780201400211]

[15] Ebrahimi HR, Saeiae RN, Maani MA. [Investigating the development of design principles of playground areas for children by focusing on age group (5-12) (case study) (Persian)] Quartery Bagh-i-Nazar. 2012; 8(19):31-42.

[16] Oostakhan M, Babaei A. Safety assessment in the urban park environment in Alborz Province, Iran. Int J Inj Contr Saf Promot. 2013; 20(1):79-84. [DOI:10.1080/17457300.2012. 674045] [PMID]

[17] Azizi JM, Danehkar A. Determination and Analysis of Critical Indicator's Standard for Urban Parks Case Study: Karaj Urban Parks. Tehran: Honar-Ha-Ye-Ziba: Memary Va Shahrsazi. 2012; 17(2):75-85.

[18] Ebrahimzadeh A, Maleki S, Hatami D. Assessing the safety status in urban paradise Case study; Parks in Izeh city. J Res Urban Plan. 2014; 5(19):57-72.

[19] S Naeini H, Jafari HR, Salehi E, Mirlouhi Falavarjani AH Child safety in parks' playgrounds (a case study in Tehran's sub-district parks). Iran Occupational Health, 2010; 7(3):37-47. 
This Page Intentionally Left Blank 